\title{
Comparison of cumulative dissipated energy between the Infiniti and Centurion phacoemulsification systems
}

This article was published in the following Dove Press journal:

Clinical Ophthalmology

22 July 2015

Number of times this article has been viewed

\author{
Ming Chen' \\ Erik Anderson ${ }^{2}$ \\ Geoffrey Hill ${ }^{3}$ \\ John J Chen ${ }^{4}$ \\ Thomas Patrianakos ${ }^{2}$ \\ 'Department of Surgery, University \\ of Hawaii, Honolulu, HI, 'Department \\ of Ophthalmology, John H Stroger, Jr \\ Hospital of Cook County, Chicago, IL, \\ ${ }^{3}$ Department of Ophthalmology, \\ UT Southwestern Medical Center, \\ Dallas, TX, ${ }^{4}$ Biostatistics Core, John A \\ Burns School of Medicine, University \\ of Hawaii, Honolulu, HI, USA
}

Purpose: To compare cumulative dissipated energy between two phacoemulsification machines.

Setting: An ambulatory surgical center, Honolulu, Hawaii, USA.

Design: Retrospective chart review.

Methods: A total of 2,077 consecutive cases of cataract extraction by phacoemulsification performed by five surgeons from November 2012 to November 2014 were included in the study; 1,021 consecutive cases were performed using the Infiniti Vision System, followed by 1,056 consecutive cases performed using the Centurion Vision System.

Results: The Centurion phacoemulsification system required less energy to remove a cataractous lens with an adjusted average energy reduction of 38\% (5.09 percent-seconds) $(P<0.001)$ across all surgeons in comparison to the Infiniti phacoemulsification system. The reduction in cumulative dissipated energy was statistically significant for each surgeon, with a range of $29 \%-45 \%(2.25-12.54$ percent-seconds $)(P=0.005-<0.001)$. Cumulative dissipated energy for both the Infiniti and Centurion systems varied directly with patient age, increasing an average of 2.38 percent-seconds $/ 10$ years.

Conclusion: The Centurion phacoemulsification system required less energy to remove a cataractous lens in comparison to the Infiniti phacoemulsification system.

Keywords: phacoemulsification, cumulative dissipated energy, Centurion Vision System, Infiniti Vision System

\section{Introduction}

Cumulative dissipated energy (CDE) is the amount of ultrasound energy used to remove a cataractous lens. Using less phacoemulsification energy has been shown to decrease corneal endothelial cell loss and may translate to better surgical outcomes. ${ }^{1-4}$ In our previous studies, we showed a mean CDE difference based on surgical location between an ambulatory surgical center (13.0 seconds) and a hospital-based surgical center (19.0 seconds) using the Infiniti Vision System (Alcon Laboratories, Inc., Fort Worth, TX, USA). ${ }^{5}$ In the second study, we found the CDE varied by surgeon and phacoemulsification technique. ${ }^{6}$

Early evaluations of the Centurion Vision System by Solomon et al have supported the manufacturer's claims, ${ }^{7}$ but these findings have yet to be substantiated in a large study. The purpose of this study was simply to compare the CDE between the single Centurion and single Infiniti phacoemulsification systems in a larger number of cases to see which one uses less CDE under similar age, sex, and complication rate $(P>0.05)$ among five surgeons in one surgical center.
Correspondence: Ming Chen Department of Ophthalmology, University of Hawaii, 55 South Kukui Street, Suite C-109, Honolulu, HI 968I3, USA

Fax + I 8085230466

Email drmingchen808@gmail.com 


\section{Patients and methods}

This retrospective study was conducted at a single-ambulatory surgical center (The Surgical Suites, LLC, Honolulu, HI, USA) from November 2012 to November 2014. All consecutive cases of cataract extraction with phacoemulsification and intraocular lens implantation performed by five surgeons were included in the study. All surgeons have performed phacoemulsification for over 20 years. A total of 2,077 consecutive cases were identified; 1,021 consecutive cases were performed using a single Infiniti phacoemulsification unit from November 2012 to November 2013 and 1,056 consecutive cases were performed using a single Centurion phacoemulsification unit from November 2013 to November 2014. Of note, the Centurion cases were performed during the first year of device adoption.

An Ozil phacoemulsification handpiece and a $0.9 \mathrm{~mm}$ 30-degree beveled Kelman tip were used in the Infiniti phacoemulsification system, while an Ozil handpiece and an Intrepid Balanced Mini tip were used in the Centurion phacoemulsification system.

Each surgeon used fluid dynamics and ultrasound settings that were preset to their own preferences. These settings and the surgical technique varied among the surgeons but were kept consistent with each individual surgeon when transitioning from the Infiniti system to the Centurion system. Scatterplots together with non-parametric lowess curves were used to display the $\mathrm{CDE}$ data.

The intraoperative metric chosen as the primary outcome measure was CDE. CDE is displayed automatically on the interface of both the Infiniti and Centurion systems and is measured in percent-seconds. CDE is the total energy dissipated at the wound site in foot position 3, including a combination of torsional and longitudinal ultrasound energies. In the conventional mode (longitudinal ultrasound), $\mathrm{CDE}$ is traditionally calculated as average ultrasound power $\times$ total ultrasound time (data on file, Alcon Laboratories, 2015). Total ultrasound time is the total time passed while the foot pedal is kept in the third position. Because torsional phacoemulsification was used in this study, CDE was calculated as torsional amplitude $\times$ torsional time $\times$ a coefficient of 0.4 . The coefficient of 0.4 is used because torsional phacoemulsification differs from conventional phacoemulsification in two aspects: the frequency of the phacoemulsification tip in the torsional mode $(32 \mathrm{kHz})$ is $80 \%$ of that in the conventional phacoemulsification $(40 \mathrm{kHz})$ and the stroke length of the phacoemulsification tip in the torsional mode $(40 \mu \mathrm{m})$ is $50 \%$ of that in the standard mode $(80 \mu \mathrm{m})$ (data on file, Alcon Laboratories, 2015). Descriptive statistics were summarized, and the means of CDE for the two systems were compared for each surgeon using two-sample $t$-tests. The complication rates under the two systems were compared using two-proportion tests. Linear mixed-effects models were used to estimate the overall difference of CDE between the two systems, while adjusting important covariates (eg, age and sex of the patient). IBM SPSS Statistics for Windows (Version 22.0) was used for data analysis, and two-sided $P$-values $<0.05$ were regarded as statistically significant. This study has been approved by the Institutional Review Board of the University of Hawaii to ethically meet the Declaration of Helsinki.

\section{Results}

A total of 2,077 consecutive phacoemulsification cases were included in the study; 1,021 cases were performed using the Infiniti phacoemulsification system and 1,056 cases using the Centurion phacoemulsification system. The age and sex demographics of the patients included in the study are demonstrated in Table 1. The mean patient age was 70.53 years, with 1,170 female and 907 male patients. There was no statistically significant difference with respect to age or sex of the patients when analyzed by an individual surgeon or between groups.

Among all five surgeons, the unadjusted average energy reduction of $\mathrm{CDE}$ when using the Centurion phacoemulsification system in comparison to the Infiniti phacoemulsification system was 4.971 (range 2.25-12.54) percent-seconds or $37 \%$ (range $29 \%-45 \%)(P$-values $<0.001)$. Each individual surgeon also demonstrated a statistically significant reduction in CDE with the Centurion system compared to the Infiniti system, as demonstrated in Table 2 and Figure 1. There was no statistically significant difference in complication rates among the two systems when analyzed by an individual surgeon or between groups (Table 3).

Based on a linear mixed-effects model, which adjusted for patient's age and sex and five surgeons, the estimated mean CDE reduction was $38 \%$ or 5.088 percent-seconds with a standard error of $0.336(P<0.001)$. In the same model, while patient sex was not significant $(P=0.33)$, a significant impact of patient age was observed $(P<0.001)$.

Figure 2 shows a scatterplot of the average CDE of the Centurion phacoemulsification system versus the Infiniti phacoemulsification system across all surgeons. The scatterplot shows that there is an increasing trend for $\mathrm{CDE}$ as the patient's age increases $(P<0.001)$.

\section{Discussion}

The Infiniti Vision System was released in 2003, followed by an upgraded torsional ultrasound handpiece in 2005. This Ozil 
Table I Summary of sex and age comparisons between Centurion and Infiniti phacoemulsification systems by an individual surgeon and all surgeons combined

\begin{tabular}{|c|c|c|c|c|c|}
\hline \multicolumn{2}{|c|}{ Surgeon } & \multirow{2}{*}{$\begin{array}{l}\text { Infiniti } \\
59.2 \%(98)\end{array}$} & \multirow{2}{*}{$\begin{array}{l}\text { Centurion } \\
60.2 \%(103)\end{array}$} & \multirow{2}{*}{$\begin{array}{l}\text { Difference (std err): } \\
\text { Centurion-Infiniti }\end{array}$} & \multirow{2}{*}{$\begin{array}{l}\boldsymbol{P} \text {-value* } \\
0.89\end{array}$} \\
\hline \multirow[t]{3}{*}{ I } & $\%$ female (total number of patients) & & & & \\
\hline & Age in years: mean (std dev) & $69.48(8.39)$ & $69.25(9.36)$ & $-0.23(1.26)$ & 0.86 \\
\hline & [range] & {$[47.0,87.0]$} & {$[46.0,94.0]$} & & \\
\hline \multirow[t]{3}{*}{2} & $\%$ female (total number of patients) & $54.7 \%(307)$ & $52.8 \%(30 I)$ & & 0.64 \\
\hline & Age in years: mean (std dev) & $70.48(9.43)$ & $70.07(9.73)$ & $-0.4 I(0.78)$ & 0.60 \\
\hline & [range] & {$[42.0,98.0]$} & {$[31.0,93.0]$} & & \\
\hline \multirow[t]{3}{*}{3} & $\%$ female (total number of patients) & $56.4 \%(408)$ & $58.1 \%(4 \mid 3)$ & & 0.62 \\
\hline & Age in years: mean (std dev) & $70.54(9.68)$ & $70.17(9.68)$ & $-0.38(0.68)$ & 0.58 \\
\hline & [range] & {$[42.0,92.0]$} & {$[37.0,94.0]$} & & \\
\hline \multirow[t]{3}{*}{4} & $\%$ female (total number of patients) & $59.1 \%(132)$ & $56.3 \%(15 I)$ & & 0.64 \\
\hline & Age in years: mean (std dev) & $71.17(11.45)$ & $72.58(10.01)$ & $\mathrm{I} .4 \mathrm{I}(\mathrm{I} .28)$ & 0.27 \\
\hline & [range] & {$[41.0,98.0]$} & {$[40.0,92.0]$} & & \\
\hline \multirow[t]{3}{*}{5} & $\%$ female (total number of patients) & $57.9 \%(76)$ & $52.3 \%(88)$ & & 0.48 \\
\hline & Age in years: mean (std dev) & $71.32(9.13)$ & $71.39(11.28)$ & $0.07(\mathrm{I} .59)$ & 0.97 \\
\hline & [range] & {$[43.0,88.0]$} & {$[43.0,91.0]$} & & \\
\hline \multirow[t]{3}{*}{ All } & $\%$ female (total number of patients) & $56.6 \%(I, 02 I)$ & $56.1 \%(1,056)$ & & 0.80 \\
\hline & Age in years: mean (std dev) & $70.56(9.69)$ & $70.50(9.88)$ & $-0.06(0.43)$ & 0.89 \\
\hline & [range] & {$[41.0,98.0]$} & {$[31.0,94.0]$} & & \\
\hline
\end{tabular}

Notes: *Statistical comparison between patients using Infiniti phacoemulsification system and those using Centurion phacoemulsification system; two-sample t-tests for continuous variables and chi-square tests for categorical variables.

Abbreviations: std err, standard error; std dev, standard deviation.

handpiece has a tip that oscillates in both a longitudinal direction (along the anterior-posterior axis), as in conventional ultrasound handpieces, and a torsional direction (swiveling from sideto-side). Torsional ultrasound has been shown to require less ultrasound energy in comparison to longitudinal ultrasound. ${ }^{8}$

The Centurion Vision System (Alcon Laboratories, Inc.) was released in the fall of 2013 with reports of being able to reduce ultrasound energy through several methods, including a newly designed phacoemulsification tip (data on file,
Alcon Laboratories, 2015). According to the manufacturer, the Intrepid Balanced Mini Tip is specifically designed for torsional ultrasound with a 50\% enhancement in sideways tip displacement (data on file, Alcon Laboratories, 2015). One drawback in the handpiece of the Infiniti system is that substantial tip motion induces friction along the shaft, resulting in unwanted corneal stromal changes at the incision site (data on file, Alcon Laboratories, 2015). The new Intrepid Balanced Mini Tip reportedly minimizes these stromal

Table 2 Summary of CDE comparisons between Centurion and Infiniti phacoemulsification systems by an individual surgeon and all surgeons combined

\begin{tabular}{|c|c|c|c|c|c|c|}
\hline \multicolumn{2}{|c|}{ Surgeon } & \multirow{2}{*}{$\begin{array}{l}\text { Infiniti } \\
7.790(6.669)\end{array}$} & \multirow{2}{*}{$\begin{array}{l}\text { Centurion } \\
5.536(4.458)\end{array}$} & \multirow{2}{*}{$\begin{array}{l}\text { Difference (std err): } \\
\text { Centurion-Infiniti } \\
-2.254(0.797)\end{array}$} & \multirow{2}{*}{$\begin{array}{l}\begin{array}{l}\text { Percent } \\
\text { difference }\end{array} \\
28.9 \%\end{array}$} & \multirow{2}{*}{$\begin{array}{l}\boldsymbol{P} \text {-value* } \\
0.005\end{array}$} \\
\hline I & CDE, seconds: mean (std dev) & & & & & \\
\hline & [range] & {$[1.23,62.83]$} & {$[0.23,27.62]$} & & & \\
\hline \multirow[t]{2}{*}{2} & CDE, seconds: mean (std dev) & $|4.75|(10.225)$ & $9.785(7.648)$ & $-4.966(0.733)$ & $33.7 \%$ & $<0.001$ \\
\hline & [range] & {$[2.56,91.86]$} & {$[0.08,61.40]$} & & & \\
\hline \multirow[t]{2}{*}{3} & CDE, seconds: mean (std dev) & $9.071(6.611)$ & $5.672(4.667)$ & $-3.399(0.399)$ & $37.5 \%$ & $<0.001$ \\
\hline & [range] & {$[0.10,51.50]$} & {$[0.07,48.56]$} & & & \\
\hline \multirow[t]{2}{*}{4} & $\mathrm{CDE}$, seconds: mean (std dev) & $27.688(14.510)$ & $15.153(9.512)$ & $-12.535(1.442)$ & $45.3 \%$ & $<0.001$ \\
\hline & [range] & {$[5.77,109.00]$} & {$[2.16,84.57]$} & & & \\
\hline \multirow[t]{2}{*}{5} & CDE, seconds: mean (std dev) & $12.664(5.394)$ & $7.739(3.648)$ & $-4.926(0.7 \mathrm{II})$ & $38.9 \%$ & $<0.001$ \\
\hline & [range] & {$[4.36,39.22]$} & {$[2.58,23.59]$} & & & \\
\hline \multirow[t]{2}{*}{ All } & CDE, seconds: mean (std dev) & $13.330(10.942)$ & $8.359(7.200)$ & $-4.97 \mathrm{I}(0.408)$ & $37.3 \%$ & $<0.001$ \\
\hline & [range] & {$[0.10,109.00]$} & {$[0.07,84.57]$} & $-5.088(0.336)^{* *}$ & $38.2 \%$ & $<0.001$ \\
\hline
\end{tabular}

Notes: *Statistical comparison between patients using Infiniti phacoemulsification system and those using Centurion phacoemulsification system; two-sample $t$-tests for continuous variables and chi-square tests for categorical variables. **Estimated $P$-value based on linear mixed-effects model, adjusting for age and sex of patients and different surgeons.

Abbreviations: CDE, cumulative dissipated energy; std err, standard error; std dev, standard deviation. 


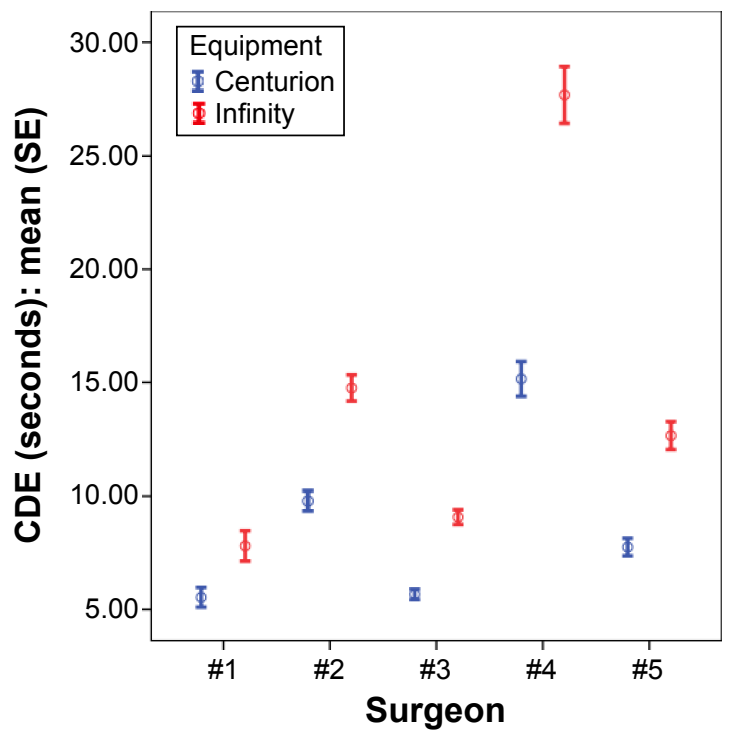

Figure I Comparison of CDE between Centurion system and Infiniti system among five surgeons.

Abbreviations: CDE, cumulative dissipated energy; SE, standard error.

changes by reducing the amount of energy transmitted to the sleeve and incision site (point defined $5.6 \mathrm{~mm}$ back from the tip). These design changes are reported to improve the thermal profile while enhancing cutting efficiency (data on file, Alcon Laboratories, 2015).

Newer generation phacoemulsification systems promise to deliver faster cataract surgery times with less energy through newly designed handpieces, tips, and software settings. The challenge remains in objectively comparing these technologies. As recently highlighted by Dr Nick Mamalis,

There is a scarcity of objective data to guide surgeons in choosing a particular ultrasound technology as well as assessing the optimum settings to use for this technology. ${ }^{9}$

To address these challenges, Dr Randall Olson's laboratory at the Moran Eye Center has created an in vitro model using porcine eyes to test various phacoemulsification

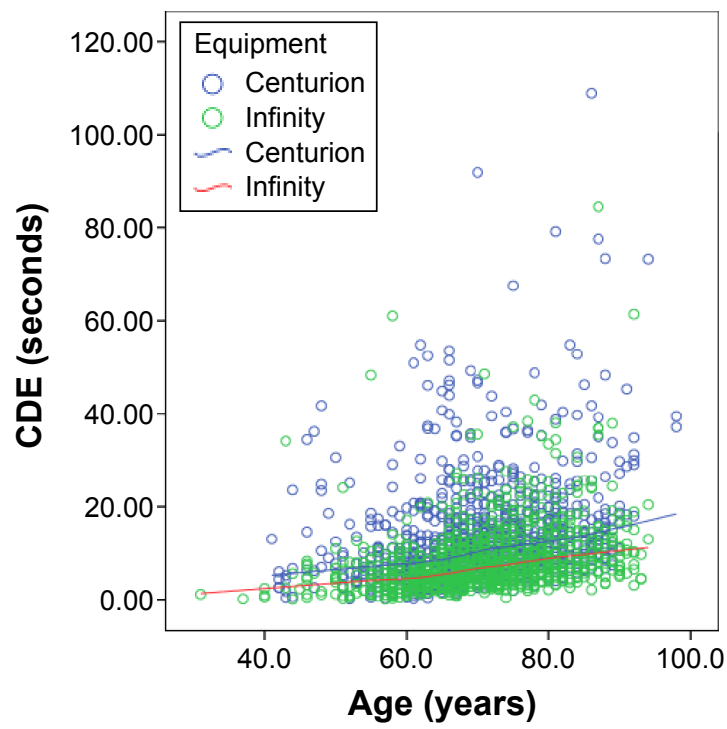

Figure 2 Comparison of CDE between Centurion system and Infinity system across age (years) among five surgeons combined. Abbreviation: $\mathrm{CDE}$, cumulative dissipated energy.

technologies and settings. ${ }^{10}$ One consistent finding with this testing model was that chatter - the phenomenon of lens material bouncing off of the phaco tip - led to the inefficient use of ultrasound energy. Using the aforementioned model, Kirk et al found that micropulse longitudinal phacoemulsification with various on and off cycles was the most efficient at reducing chatter with an on-time of 6 ms. ${ }^{11}$

Another method to decrease chatter and increase efficiency is through the use of torsional ultrasound. Liu et al showed that total ultrasound time and energy could be reduced through the use of a torsional ultrasound Ozil handpiece in comparison to conventional longitudinal ultrasound. ${ }^{8}$ In our study, an identical handpiece with torsional ultrasound was used with both the Infiniti and Centurion systems. The Ozil handpiece oscillates at a frequency of $32 \mathrm{kHz}$ with a side-to-side movement that has a shearing effect and cuts nuclear material in both directions at the tip, resulting in less repulsion of lenticular material from the phaco tip. ${ }^{8}$

Table 3 Comparison of surgical complication rates between Centurion and Infiniti phacoemulsification systems by an individual surgeon and all surgeons combined

\begin{tabular}{|c|c|c|c|c|c|c|}
\hline & Surgeon I & Surgeon 2 & Surgeon 3 & Surgeon 4 & Surgeon 5 & All surgeons \\
\hline \multicolumn{7}{|l|}{ All complications } \\
\hline Infiniti: n (\%) & $\mathrm{I}(\mathrm{I} .0 \%)$ & $2(0.7 \%)$ & $3(0.7 \%)$ & $6(4.5 \%)$ & $\mathrm{I}(\mathrm{I} .3 \%)$ & $13(1.3 \%)$ \\
\hline Centurion: n (\%) & I (I.0\%) & $5(1.7 \%)$ & $6(1.5 \%)$ & $6(4.0 \%)$ & $0(0.0 \%)$ & $18(1.7 \%)$ \\
\hline$P$-value* & 1.00 & 0.29 & 0.51 & 1.00 & 0.47 & 0.48 \\
\hline \multicolumn{7}{|c|}{ Posterior capsule rupture with anterior vitrectomy } \\
\hline Infiniti: n (\%) & $\mathrm{I}(\mathrm{I} .0 \%)$ & $\mathrm{I}(0.3 \%)$ & $\mathrm{I}(0.2 \%)$ & $4(3.0 \%)$ & $0(0.0 \%)$ & $7(0.7 \%)$ \\
\hline Centurion: n (\%) & $0(0.0 \%)$ & $0(0.0 \%)$ & $3(0.7 \%)$ & $2(1.3 \%)$ & $0(0.0 \%)$ & $5(0.5 \%)$ \\
\hline$P$-value* & 0.49 & 1.00 & 0.63 & 0.43 & 1.00 & 0.58 \\
\hline
\end{tabular}

Note: ${ }^{*} P$-values were based on exact tests of equality of two proportions. 
In our study, we sought to determine if the new Centurion phacoemulsification system was more efficient than its predecessor, as claimed by the manufacturer. Using a single intraoperative metric of $\mathrm{CDE}$, we found an adjusted average energy reduction of $38 \%$ ( 5.088 percent-seconds) when using the Centurion system. Although the amount of $\mathrm{CDE}$ reduction varied significantly between surgeons, every surgeon achieved a reduction in energy used with a range of $29 \%-45 \%$. These findings are consistent with a small-scale prospective randomized clinical study by Solomon et al in which the mean CDE when using the Centurion system was found to be 2.78 percent-seconds less than with the Infiniti system. ${ }^{7}$ Our findings also demonstrated that CDE was higher for older patients who underwent surgery with both the Centurion and Infiniti systems. On average, for every 10 years of increase in patient age, we found a 2.38 unit increase in $\mathrm{CDE}(P<0.001)$. This was likely due to an increase in nucleus density with increasing age. Liu et al reported similar findings with a consistent increase in $\mathrm{CDE}$ in eyes with higher grades of nucleus density. ${ }^{8}$

According to the manufacturer, the mechanism of energy reduction with the Centurion system is enhancement of torsional ultrasound efficiency through a redesigned tip (data on file, Alcon Laboratories, 2015). The Intrepid Balanced Mini Tip offers $50 \%$ more lateral movement at the tip leading to an increased emulsification effect while reducing shaft movement at the incision site (data on file, Alcon Laboratories, 2015). ${ }^{12}$ This reduced movement and heat production in the wound minimizes unwanted corneal stromal changes and subsequent complications such as wound leaks and shifts in astigmatism (data on file, Alcon Laboratories, 2015).

Of note, there are other improvements unique to the Centurion phacoemulsification system aimed at stabilizing fluidic dynamic energy, which can also have a pronounced negative effect on ocular structures. ${ }^{13}$ The Centurion system uses an active fluid dynamic management system that applies pressure directly to the irrigation bag. In comparison, older systems like the Infiniti use a gravity-based fluidic system that is more prone to wide fluctuations in intraocular pressure (data on file, Alcon Laboratories, 2015). The Centurion system is able to constantly adjust to and minimize these fluctuations, resulting in a more stable anterior chamber and minimizing abrupt swings in aspiration flow rate, pressure, and rate of vacuum (data on file, Alcon Laboratories, 2015). In this study, we sought to examine only CDE for comparison between phacoemulsification systems, but comparing other characteristics and intraoperative metrics is a potential area of future study.
Our study is limited in several aspects. First, our study is retrospective, not prospective, and is not randomized. In addition, an ideal study would have used an in vitro method to objectively measure ultrasound efficiency rather than relying on the phacoemulsification platform's calculation. In the future, we believe it will be important to develop and use in vitro models, not only to optimize modalities of phacoemulsification from software variations to tip design but also to create prospective, objective, and direct comparisons of different platforms. While we did not report on visual acuity or complication rates, previous studies have shown that using less energy causes less corneal endothelial cell loss ${ }^{1-4}$ and results in better immediate postoperative visual acuities. ${ }^{8}$ We believe that this statistically and clinically significant reduction in energy has the potential to improve visual outcomes.

A particular strength of this study is the large number of cases included and the fact that several surgeons were included. Though the results were influenced by different ultrasound settings and surgical techniques, the fact that our findings were consistent across all surgeons suggests that the results may be broadly applicable.

\section{Conclusion}

The Centurion phacoemulsification system required less energy to remove a cataractous lens with an adjusted average energy reduction of $38 \%$ per surgeon in comparison to the Infiniti phacoemulsification system.

\section{Acknowledgments}

John J Chen was partially supported by grants U54MD007584, G12MD007601, and P20GM103466 from the National Institutes of Health (NIH). The content is solely the responsibility of the authors and does not necessarily represent the official views of the NIH.

\section{Disclosure}

The authors report no conflicts of interest in this work.

\section{References}

1. Pirazzoli B, D’Eliseo D, Ziosi M, Acciarri R. Effects of phacoemulsification time on the corneal endothelium using phacofracture and phaco chop techniques. J Cataract Refract Surg. 1996;22(7): 967-969.

2. Kreisler KR, Mortenson SW, Mamalis N. Endothelial cell loss following "modern" phacoemulsification by a senior resident. Ophthalmic Surg. 1992;23(3):158-160.

3. Colvard DM, Kratz RP, Mazzocco TR, Davidson B. Endothelial cell loss following phacoemulsification in the pupillary plane. J Am Intraocul Implant Soc. 1981;7(4):334-336.

4. Hayashi K, Hayashi H, Hakao F, Kayashi F. Risk factors for corneal endothelial injury during phacoemulsification. J Cataract Refract Surg. 1996;22(8):1079-1084. 
5. Chen M, Chen M. Comparison of CDE data in phacoemulsification between an open hospital-based ambulatory surgical center and a free-standing ambulatory surgical center. Clin Ophthalmol. 2010;4: 1287-1289.

6. Chen M, Sweeney HW, Luke B, Chen M, Brown MA. Retrospective randomized study to compare the energy delivered using CDE with different techniques and OZil settings by different surgeons in phacoemulsification. Clin Ophthalmol. 2009;3:401-403.

7. Solomon KD, Lorente R, Cionni RJ, Fanney D. Prospective, randomized clinical study using a new phaco system with intraocular system target pressure control. Paper presented at: The ASCRS Meeting; April 28, 2014; Boston, MA.

8. Liu Y, Zeng M, Liu X, et al. Torsional mode versus conventional ultrasound mode phacoemulsification. J Cataract Refract Surg. 2007; 33(2):287-292.

9. Mamalis N. Which phacoemulsification modalities are the best? Comparing apples to apples. J Cataract Refract Surg. 2015;41:255-256.
10. Oakey ZB, Jensen JD, Zaugg BE, Radmall BR, Pettey JH, Olson RJ. Porcine lens nuclei as a model for comparison of 3 ultrasound modalities regarding efficiency and chatter. J Cataract Refract Surg. 2013;39: 1248-1253.

11. Kirk KR, Ronquillo C Jr, Jensen JD, et al. Optimal on-time duty cycle for micropulse technology. J Cataract Refract Surg. 2014; 40:1545-1548.

12. Tjia KF. Novel balanced phaco tip for microcoaxial tortional phaco. Paper presented at: The ASCRS Meeting, April 27, 2014; Boston, MA.

13. Rekas M, Montés-micó R, Krix-jachym K, Kluś A, Stankiewicz A, Ferrer-blasco T. Comparison of torsional and longitudinal modes using phacoemulsification parameters. J Cataract Refract Surg. 2009; 35(10):1719-1724
Clinical Ophthalmology

\section{Publish your work in this journal}

Clinical Ophthalmology is an international, peer-reviewed journal covering all subspecialties within ophthalmology. Key topics include: Optometry; Visual science; Pharmacology and drug therapy in eye diseases; Basic Sciences; Primary and Secondary eye care; Patient Safety and Quality of Care Improvements. This journal is indexed on

\section{Dovepress}

PubMed Central and CAS, and is the official journal of The Society of Clinical Ophthalmology (SCO). The manuscript management system is completely online and includes a very quick and fair peer-review system, which is all easy to use. Visit http://www.dovepress.com/ testimonials.php to read real quotes from published authors. 